\author{
Dariusz MIKIELEWICZ ${ }^{1}$ \\ Jarosław MIKIELEWICZ ${ }^{2}$ \\ Jan WAJS ${ }^{1,2}$
}

\title{
ANALIZA MOŻLIWOŚCI WSPÓŁPRACY ELEKTROWNI O MOCY 900MW Z UKŁADEM ODZYSKU CIEPŁA ZASILAJĄCYM ORC
}

\begin{abstract}
W pracy przeanalizowano kwestie związane z wykorzystaniem ciepła odpadowego z bloku energetycznego elektrowni o parametrach nadkrytycznych o mocy 900MW. Zagadnieniem nad którym skupiono uwage jest pełne wykorzystanie potencjału ciepła odpadowego ze spalin, w postaci strumienia ciepła gorącej wody o mocy 200MW i temperaturze $90^{\circ} \mathrm{C}$. Ciepło to wykorzystane jest do grzania układu ORC. Temperatura nośnika ciepła jest niewystarczająca, aby uzyskać atrakcyjne sprawności termiczne obiegu ORC i dlatego obieg ten jest dodatkowo dogrzewany ciepłem pary upustowej. W pracy przedstawiono model numeryczny układu hybrydowego łączącego blok nadkrytyczny o mocy 900 MWe z obiegiem ORC. Ponadto przedstawiono obliczenia numeryczne bloku nadkrytycznego dla płynu roboczego etanolu, przy wykorzystaniu dwóch upustów pary wodnej do końcowego odparowania czynnika ORC. Do analizy parametrów eksploatacyjnych obiegu posłużono się komercyjnym kodem Aspen Plus.
\end{abstract}

Słowa kluczowe: odzysk ciepła, organiczny obieg Rankine'a, elektroenergetyka

\section{Wprowadzenie}

Pewne, bezpieczne i możliwie tanie dostawy energii stanowią zasadniczą kwestię dla utrzymania ekonomicznego rozwoju oraz bezpieczeństwa społeczeństw. Ostatnio obserwowane obniżenie poziomu bezpieczeństwa energe-

\footnotetext{
${ }^{1}$ Autor do korespondencji/corresponding author: Dariusz Mikielewicz, Politechnika Gdańska, Wydział Mechaniczny, Narutowicza 11/12, 80-231 Gdańsk, e-mail: dariusz.mikielewicz@pg.gda.pl

${ }^{2}$ Instytut Maszyn Przepływowych PAN, Fiszera 14, 80-231 Gdańsk, e-mail: jaroslaw.mikielewicz@imp.gda.pl, janwajs@pg.gda.pl
} 
tycznego, pogłębiające się zmiany klimatu i rosnące potrzeby energetyczne stanowią wyzwanie dla nauki i techniki. Autorzy postawili sobie za zadanie przybliżyć rolę technologii konwersji energii, a w szczególności potencjału ukrytego w odzysku energii odpadowej w odniesieniu do elektrowni węglowych. Jest to zagadnienie dotychczas nie rozpatrywane, gdyż sądzono że jest to proces mało opłacalny. W obecnych czasach rachunek ekonomiczny wskazuje na opłacalność technologii odzysku ciepła $\mathrm{z}$ układu siłowni węglowych. W przypadku tradycyjnej technologii z siłowniami parowymi mają temu służyć działania poprawiające sprawność takie jak:

- zwiększenie nadkrytycznych parametrów pary,

- instalowanie układów dla odzysku ciepła odpadowego,

- podsuszanie węgla brunatnego,

- wysokosprawna kogeneracja itd.

Wynika stąd, że instalacje do odzysku ciepła odpadowego z bloków energetycznych są jednymi z priorytetowych problemów rozwoju energetyki zawodowej.

W artykule przedstawiono nową i oryginalną koncepcję współpracy niskotemperaturowego obiegu ORC z blokiem turbiny parowej [1]. Ze względu na stosunkowo niską temperaturę strumienia ciepłej wody parametry, które mamy do wykorzystania w pracy, a co za tym idzie wydajności cieplne możliwe do uzyskania w systemie ORC są niezadawalające dla układu ORC. Z tego względu w pracy szczegółowo przedstawiono koncepcję dogrzewu obiegu ORC za pomocą pary pobieranej z upustów pary z części niskoprężnej turbiny.

\section{Koncepcja odzysku ciepła}

Do rozważań przyjęto najprostszy obieg Rankina z czynnikiem organicznym bez przegrzewu pary przed turbiną. Ze względu na rozpatrywane potencjalne czynniki robocze możliwe do wykorzystania w instalacji ORC rozpatrzono obiegi bez oraz z regeneracją cieplną obiegu. Obieg bez regeneracji ciepła, jako prostszy, ma zapewnić możliwie małe powierzchnie wymiany ciepła w obiegu, decydujące o wymiarach siłowni.

Schemat zastosowanej turbiny parowej współpracującej z obiegiem ORC przedstawiono na rysunku 1. Podstawowymi elementami układu ORC są: kocioł (parownik), turbina, skraplacz i pompa zasilająca. W rozpatrywanym rozwiązaniu wytwornica pary w ORC składa się z przynajmniej dwóch wymienników. Obieg ORC, dogrzewany parą upustową w celu efektywnego wykorzystania ciepła odpadowego, jest ogrzewany w przynajmniej w dwóch wymiennikach ciepła, przy czym w pierwszym (WC1) doprowadzone jest ciepło odpadowe, natomiast w drugim (WC2) ciepło skraplającej się pary pochodzącej z upustu, lub z innego źródła ciepła podającego parę. W przypadku korzystania $\mathrm{z}$ większej liczby upustów, czy tak jak zaproponowano w dalszej części opisu 
wykorzystanie ciepła z instalacji wychwytu $\mathrm{CO}_{2}$, konieczne jest wprowadzenie kolejnych wymienników ciepła. Para, która oddała część ciepła w wymienniku WC2 kierowana jest do wymiennika regeneracyjnego obiegu parowego. Zaletą tego rozwiązania jest efektywne wykorzystanie niskotemperaturowego ciepła odpadowego będącego w postaci strumienia gorącej wody lub gazu. W przypadku braku dogrzania parą upustową wykorzystanie niskotemperaturowego źródła ciepła odpadowego jest jedynie częściowe. W takim przypadku albo musimy zastosować bardzo duże natężenie przepływu nośnika ciepła co skutkuje niepełnym wykorzystaniem potencjału ciepła odpadowego (nie obniżamy znacząco jego temperatury), bądź też musimy obniżyć temperaturę pary czynnika roboczego przed turbiną ORC, co bezpośrednio przekłada się na obniżenie sprawności obiegu ORC. Rozwiązanie, które rozwijano w trakcie prac polegało na rozważeniu możliwości wykorzystania całości ciepła odpadowego, jakie było w dyspozycji, czyli strumienia gorącej wody o temperaturze $90^{\circ} \mathrm{C}$ i mocy cieplnej 200MWt. Zbudowano model matematyczny w programie Aspen Plus i badano nim możliwości optymalnego zagospodarowania ciepła odpadowego.

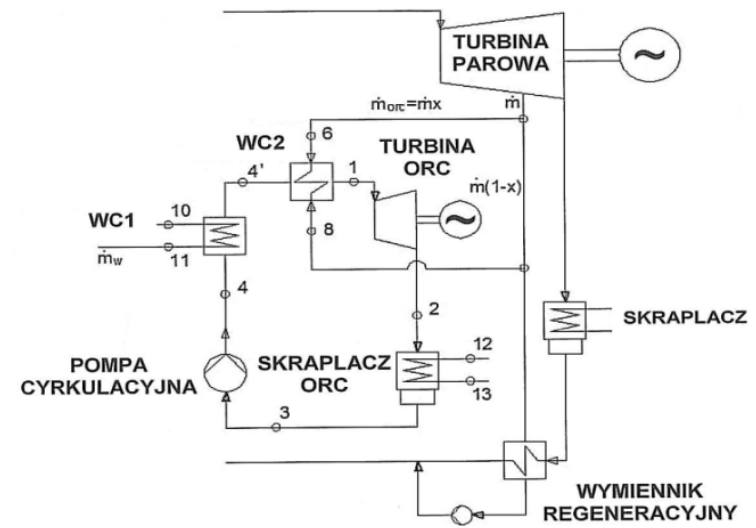

Rys. 1 Schemat siłowni współpracującej z obiegiem ORC

Fig. 1 Schematic diagram of the power plant cooperating with ORC cycle

\section{Model numeryczny układu hybrydowego}

Schemat cieplny wyjściowego bloku elektrowni przedstawiono na Rys. 2. Projekt bloku referencyjnego zakłada w obiegu turbinę trzyczęściową składającą się z części: WP, SP i NP. Część wysokoprężna wyposażona jest w jeden upust skierowany do wymiennika regeneracyjnego wysokoprężnego W7. Pozostała część strumienia pary rozpręża się do ciśnienia 6.3MPa na wyjściu z turbiny. Po skierowaniu części strumienia masy pary na wymiennik W6 pozostały strumień trafia na międzystopniowy przegrzew pary. $Z$ kolei część SP posiada dwa upusty pierwszy skierowany najpierw na schładzacz pary a dalej na wy- 
miennik regeneracyjny wysokoprężny W5 oraz drugi dostarczający parę do odgazowywacza. Z części średnioprężnej większość pary kierowana jest do NP, a pozostała część pary trafia do wymiennika W4. Część niskoprężna wyprowadza trzy upusty na wymienniki regeneracyjne niskoprężne W3, W2 i W1. Po opuszczeniu NP strumień pary trafia do skraplacza i dalej kondensat trafia do pompy skroplin. Dodatkowe pompy skroplin posiada wymiennik W2 i W4. Pompa główna zasilająca znajduje się za odgazowywaczem ODG.

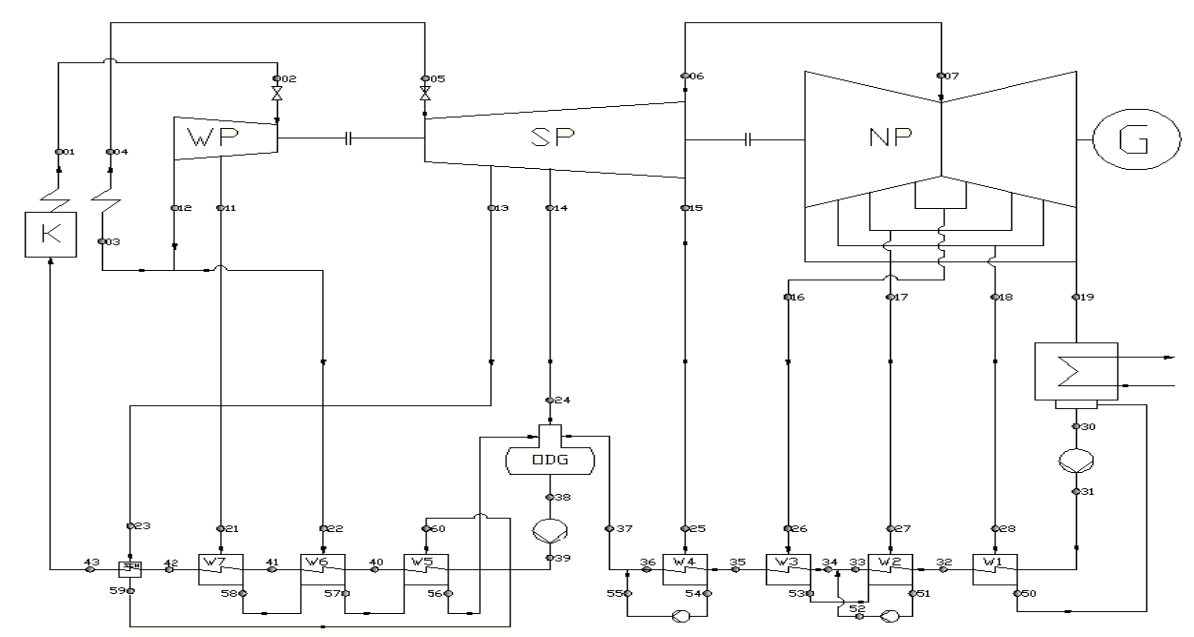

Rys. 2 Schemat cieplny bloku nadkrytycznego, gdzie: K - kocioł, WP, SP, NP - część wysokoprężna, średnioprężna i niskoprężna turbiny parowej, SCH - schładzacz, ODG - odgazowywacz, W1 $\div$ W4 - wymienniki regeneracyjne niskoprężne, W5 $\div$ W7 - wymienniki regeneracyjne wysokoprężne

Fig. 2 Heat schematic of the supercritical power plant unit: K - boiler, SP, NP - high-, medium and low-pressure parts of steam turbine, SCH - cooler, ODG - degasser, W1 $\div \mathrm{W} 4$ - low-pressure regeneration exchangers, W5 $\div \mathrm{W} 7$ - high-pressure regeneration exchangers

Przy tworzeniu modelu numerycznego współpracy bloku 900 MWe z obiegiem ORC założono, że do dyspozycji jest strumień ciepłej wody o mocy $200 \mathrm{MWt}$ i temperaturze $90^{\circ} \mathrm{C}$. Woda uzyskuje powyższą temperaturę w systemie odzysku ciepła ze spalin i może być skierowana zarówno do podgrzewu czynnika krążącego w obiegu ORC, jak i do regeneracji ciepła w wymiennikach niskoprężnych. Dodatkowym założeniem było wykorzystanie części ciepła ze skraplającego się czynnika do podgrzewu kondensatu pary wodnej w pierwszym wymienniku niskoprężnym. Oznacza to, że w układzie ORC górne źródła ciepła oprócz wody z systemu odzysku ciepła o temperaturze $90^{\circ} \mathrm{C}$ wykorzystuje ciepło z jednego lub dwóch upustów pary z turbiny parowej. Rozpatrywane w pracy upusty pary mają następujące parametry termiczne: 
- upust nr 16: temperatura pary $227^{\circ} \mathrm{C}$, ciśnienie pary 2.469 bar, co odpowiada temperaturze kondensacji przy danym ciśnieniu równej $127^{\circ} \mathrm{C}$. Powinno to umożliwić osiągnięcie temperatury czynnika roboczego ORC przed turbiną na poziomie $122^{\circ} \mathrm{C}$,

- upust nr 17: temperatura pary $\mathrm{t}=137.1^{\circ} \mathrm{C}$, ciśnienie pary $\mathrm{p}=0.929 \mathrm{bar}$, co odpowiada temperaturze kondensacji przy danym ciśnieniu równej $96.8^{\circ} \mathrm{C}$,

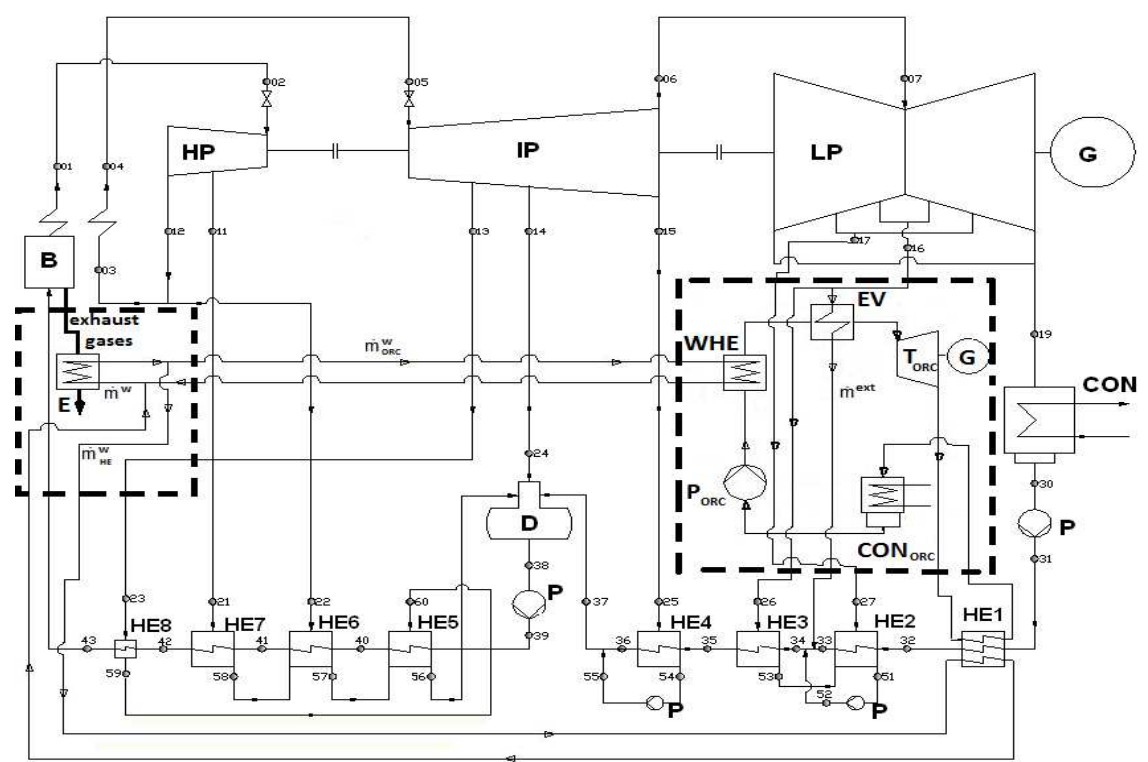

Rys. 3 Ogólny schemat układu cieplnego bloku nadkrytycznego współpracującego z obiegiem ORC, gdzie: B - kocioł, HP, IP, LP - część wysokoprężna, średnioprężna i niskoprężna turbiny parowej, P - pompa, CON - skraplacz, G - generator, HE8 - schładzacz, D - odgazowywacz, HE1- HE4 - wymienniki regeneracyjne niskoprężne, HE5- HE7 - wymienniki regeneracyjne wysokoprężne, E - ekonomizer, WHE - wymiennik ciepła odpadowego podgrzewający czynnik ORC, EV - wytwornica pary czynnika ORC, $\mathrm{T}_{\mathrm{ORC}}$ - turbina ORC, $\mathrm{P}_{\mathrm{ORC}}-$ pompa $\mathrm{ORC}, \mathrm{CON}_{\mathrm{ORC}}$ - skraplacz ORC

Fig. 2 General schematic of the heat system of supercritical power unit cooperating with ORC cycle: B - boiler, HP, IP, LP - high-, medium and low-pressure parts of steam turbine, P - pump, CON - condenser, G - generator, HE8 - cooler, D - degasser, HE1-HE4 - low-pressure regeneration exchangers, HE5-HE7 - high-pressure regeneration exchangers, E - economizer, WHE waste heat exchanger for heating of ORC medium, $\mathrm{EV}$ - vapour generator of ORC medium, $\mathrm{T}_{\mathrm{ORC}}$ -ORC turbine, $\mathrm{P}_{\mathrm{ORC}}-\mathrm{ORC}$ pump, $\mathrm{CON}_{\mathrm{ORC}}-\mathrm{ORC}$ condenser

W obliczeniach obiegu ORC przyjęto, że sprawność turbiny i pompy wynoszą odpowiednio $\eta_{i}=0,9$ i $\eta_{i}=0,85$ oraz założono $\Delta T=5 \mathrm{~K} \mathrm{w}$ wymienniku między czynnikiem niskowrzącym a woda/parą oddającą/pobierającą ciepło. Ponadto założono, że wrzenie czynnika ORC będzie przebiegać w parametrach podkrytycznych, a woda podgrzana w systemie odzysku ciepła ze spalin do 
temperatury $90^{\circ} \mathrm{C}$ przekazuje ciepło do zarówno do podgrzewu czynnika w instalacji ORC jako i regeneracji niskoprężnej oraz przy tym ostatnim procesie ochładza się do temperatury $50^{\circ} \mathrm{C}$. W przeprowadzonych analizach zmieniano strumień masy pary pobieranej z upustu oznaczonego na Rys. 3 liczbą 16 na potrzeby obiegu ORC przyjęto w zakresie: $\dot{\mathrm{m}}_{\mathrm{ORC}}^{\text {upust }}=0-23 \mathrm{~kg} / \mathrm{s}$ jak również z upustu oznaczonego jako $17-\dot{\mathrm{m}}_{\mathrm{ORC}}^{\text {upust }}=0-20 \mathrm{~kg} / \mathrm{s}$. Całkowita kondensacja pary z upustu 16 oddaje ciepło czynnikowi niskowrzącemu w ilości $\dot{\mathrm{Q}}_{\mathrm{ORC}, 1}^{\mathrm{S}}=51.1$ MWt, natomiast z upustu 17 odpowiednio $\dot{\mathrm{Q}}_{\mathrm{ORC}, 2}^{\mathrm{s}}=44,1 \mathrm{MWt}$.

W pracy przedstawiono obliczenia numeryczne bloku nadkrytycznego dla etanolu jako płynu roboczego, tym razem przy wykorzystaniu dwóch upustów pary wodnej do końcowego odparowania czynnika ORC. Było to podyktowane faktem, że w dotychczasowych pracach etanol, pomimo faktu, że termodynamicznie jest najlepszym z dotychczas wykorzystywanych czynnikiem roboczym, to jednak w konfrontacji z innymi czynnikami okazywało się, że brak jest w instalacji upustów ciepła wymaganej jego ilości, żeby w całości wykorzystać posiadane ciepło odpadowe. Założono, że strumień ciepła w wodzie $200 \mathrm{MWt}$ i temperaturze $t_{h}^{w}=90^{\circ} \mathrm{C}$ odbierany jest w ekonomizerze E (Rys. 3). Woda uzyskuje powyższą temperaturę w systemie odzysku ciepła ze spalin i może być skierowana zarówno do podgrzewu czynnika krążącego w obiegu ORC (EV), jak i do regeneracji ciepła w wymiennikach niskoprężnych (HE1). W przypadku skraplacza ORC przyjęto, że zachodzi w nim skraplanie czynnika niskowrzącego przy tej samej temperaturze, co $\mathrm{w}$ obiegu bazowym, to jest $\mathrm{w} t_{c o n}=32,8^{\circ} \mathrm{C}$.

\section{Wyniki obliczeń}

Ciśnienie nasycenia etanolu $\mathrm{p}_{\mathrm{CR}}=4,6$ bar zostało tak dobrane, aby wrzenie czynnika w obiegu ORC zachodziło w temperaturze $122^{\circ} \mathrm{C}$. Zmianie podlegał strumień masowy $\dot{\mathrm{m}}_{\mathrm{CR}}$ etanolu od wartości $\dot{\mathrm{m}}_{\mathrm{CR}}=60 \mathrm{~kg} / \mathrm{s}$ dla maksymalnego strumienia masy upustu $\dot{\mathrm{m}}_{\mathrm{ORC}}^{\text {upust }}=23 \mathrm{~kg} / \mathrm{s}$, aż do wartości $\dot{\mathrm{m}}_{\mathrm{CR}}=41,7 \mathrm{~kg} / \mathrm{s}$ dla strumienia masy upustu wynoszącego $16 \mathrm{~kg} / \mathrm{s}$, czyli na regenerację w wymienniku W3 kierowano tylko $7 \mathrm{~kg} / \mathrm{s}$ pary, co pozwalało osiągnąc temperaturę $t_{k o t}$ $=309,3^{\circ} \mathrm{C}$ wodzie powrotnej do kotła. Zmniejszanie strumienia masowy upustu $\dot{\mathrm{m}}_{\text {ORC }}^{\text {upust }}$ kierowanego na wytworzenie pary etanolu, z kolei zwiększało strumień kierowany na regenerację w wymienniku W3. Przy strumieniu $\dot{\mathrm{m}}_{\mathrm{ORC}}^{\text {upust }}=16 \mathrm{~kg} / \mathrm{s}$ osiągnięto prawie ten sam rozkład temperatury w części niezmodyfikowanej, czyli w wymiennikach W4, W5, itd, jak przed modyfikacją. Dalsze zwiększanie strumienia kierowanego na regenerację w wymienniku W3 jest, zatem niewskazane. Wyniki obliczeń dla etanolu przy wykorzystaniu wody o temperaturze 90 ${ }^{\circ} \mathrm{C}$ grzejącej obieg ORC i upuście pary na organiczny obieg Clausiusa - Rankine'a zaprezentowano w Tabeli 1. 
Tabela 1. Wyniki obliczeń wpływu obiegu ORC na obieg nadkrytyczny dla etanolu

Table 1. Results of calculations of ORC cycle on supercritical cycle for ethanol

\begin{tabular}{|c|c|c|c|c|c|c|c|c|c|c|c|}
\hline Parametr & \multirow{3}{*}{$\begin{array}{c}\text { Jednostka } \\
{[\mathrm{kg} / \mathrm{s}]}\end{array}$} & \multicolumn{4}{|c|}{ Wartość parametru dla etanolu } & $\dot{Q}_{d}$ & [MWt] & 1731,1 & 1732,2 & 1741.9 & 1749,2 \\
\hline \multirow{2}{*}{$\dot{m}_{\text {ORC }}^{\text {upust }}$} & & \multirow{2}{*}{0,0} & \multirow{2}{*}{16,0} & \multirow{2}{*}{20,0} & \multirow{2}{*}{23,0} & & & & & & \\
\hline & & & & & & $\eta_{o d}$ & [\%] & 51,960 & 52,627 & 52,442 & 52,303 \\
\hline $\mathrm{t}_{\mathrm{CR}}$ & {$\left[{ }^{\circ} \mathrm{C}\right]$} & - & 122 & 122 & 122 & $\Delta \eta_{\text {od }}$ & [\%] & - & 0,667 & 0,482 & 0,343 \\
\hline$\dot{m}_{C R}$ & {$[\mathrm{~kg} / \mathrm{s}]$} & - & 41,7 & 52,2 & 60,0 & $\dot{Q}_{t c}{ }^{w}$ & [MWt] & - & 7,0 & 8,7 & 10,0 \\
\hline$l_{t C R}$ & {$[\mathrm{~kJ} / \mathrm{kg}]$} & - & 182,98 & 182,98 & 182,98 & $\dot{Q}_{t c} p$ & {$[\mathrm{MWt}]$} & - & 37,0 & 46,3 & 53,2 \\
\hline $\begin{array}{l}q_{d C R} \\
\eta_{t C R}\end{array}$ & $\frac{[\mathrm{kJ} / \mathrm{kg}]}{[\%]}$ & - & $\begin{array}{c}1053,24 \\
17,37\end{array}$ & $\begin{array}{c}1053,24 \\
17,37\end{array}$ & $\begin{array}{c}1053,24 \\
17,37\end{array}$ & $\dot{Q}_{t c}$ & {$[\mathrm{MWt}]$} & - & 44,0 & 54,9 & 63,2 \\
\hline$N_{t C R}$ & [MW] & - & $\begin{array}{c}7,64 \\
91159\end{array}$ & $\begin{array}{c}9,55 \\
913\end{array}$ & $\begin{array}{c}10,98 \\
01480\end{array}$ & $t_{k o t}$ & {$\left[{ }^{\circ} \mathrm{C}\right]$} & 310,0 & 309,3 & 306,2 & 303,9 \\
\hline $\begin{array}{c}N_{\text {elBO }} \\
\Delta N_{\text {elBO }}\end{array}$ & $\begin{array}{l}{[\mathrm{MWe}]} \\
{[\mathrm{MWe}]}\end{array}$ & $\begin{array}{c}899,49 \\
- \\
\end{array}$ & $\begin{array}{c}911,59 \\
12,1 \\
\end{array}$ & $\begin{array}{c}913,48 \\
14,0 \\
\end{array}$ & $\begin{array}{c}914,89 \\
15,4 \\
\end{array}$ & $\dot{Q}^{90}{ }_{W}=\dot{Q}_{\text {reg }}$ & {$[\mathrm{MWt}$} & 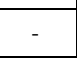 & 89,4 & 89,4 & 89,4 \\
\hline
\end{tabular}

$\mathrm{W}$ obiegu najpierw następuje pobór ciepła $\mathrm{z}$ wody, a następnie $\mathrm{z}$ pary wodnej $\mathrm{z}$ upustów, czyli spada wartość regeneracji wody w wymienniku W3 wraz ze wzrostem strumienia masy upustu na obieg ORC $\dot{\mathrm{m}}_{\mathrm{ORC}}^{\text {upust }} \mathrm{i}$ wzrasta ciepło dostarczane do pary $\mathrm{z}$ kotła, aby $\mathrm{z}$ wody o temperaturze $\mathrm{t}_{\mathrm{kot}}$ wytworzyć parę $\mathrm{o}$ wymaganych parametrach. Należy dodać, iż woda o temperaturze $90^{\circ} \mathrm{C}$ używana jest zarówno do regeneracji jak i podgrzewu czynnika niskowrzącego przekazała strumień ciepła do kondensatu wynoszący $\dot{Q}^{90}{ }_{W}=89,4 \mathrm{MWt}$, co skutkuje temperaturą skroplin w wymienniku niskoprężnym $\mathrm{W} 1$ równą $87^{\circ} \mathrm{C}$. Obieg ORC pracuje przy użyciu etanolu w stałym zakresie temperatur i uzyskuje sprawność $\eta_{t C R}=17,37 \%$. Uzyskane wyniki wskazują, wyraźny trend wzrostu mocy obiegu C-R $N_{t C R}$ i spadek sprawności odniesienia $\eta_{\text {od }}$ wraz ze wzrostem strumienia masy upustu na obieg ORC $\dot{\mathrm{m}}_{\mathrm{ORC}}^{\text {upust }}$. Należy również stwierdzić, że zaproponowana modyfikacja zapewniła przyrost mocy elektrycznej turbiny parowej brutto $\mathrm{o} \Delta \mathrm{N}_{\mathrm{elB}}=4,57 \mathrm{MWe}$. Z kolei obieg ORC przy wykorzystaniu etanolu zapewnia moc obiegu ORC $N_{t C R}=7,64 \mathrm{MW}$ przy $\dot{\mathrm{m}}_{\mathrm{ORC}}^{\text {upust }}=16 \mathrm{~kg} / \mathrm{s}$. Co daje łączny przyrost mocy elektrycznej $\Delta N_{\text {elBO }}=12,1 \mathrm{MWe}$ oraz przyrost sprawności odniesienia $\Delta \eta_{o d}=0,667 \%$. Do wykorzystania całego strumienia ciepła odpadowego o wartości $200 \mathrm{MWt}$ skierowanego na podgrzew etanolu, należy dostarczyć na dalszy podgrzew do temperatury $120^{\circ} \mathrm{C}$ strumień ciepła o wartości 146,21 MWt. Z kolei na przemianę fazową czynnika jest potrzebny strumień ciepła o wartości 905,24 MWt. Wówczas strumień masy etanolu wynosi $\dot{m}_{\text {ORC }}=1189,20 \mathrm{~kg} / \mathrm{s}$, a moc turbiny ORC odpowiednio $N_{t, O R C}=219,00 \mathrm{MWe}$.

\section{Podsumowanie}

W pracy przedstawiono oryginalne rozwiązanie dogrzewu obiegu ORC, którego celem podstawowym jest wykorzystanie ciepła odpadowego ze spalin w obiegu bloku referencyjnego w postaci strumienia gorącej wody o temperaturze $90^{\circ} \mathrm{C}$ i mocy $200 \mathrm{MWt}$. Temperatura tej wody jest zbyt niska, aby uzyskać 
zadowalającą sprawność obiegu ORC. Z tego względu obieg ORC jest dogrzewany dodatkowo ciepłem kondensującej się pary z upustów części niskoprężnej turbiny parowej. Uzyskano zadowalające wyniki, zachęcające do dalszych prac w tym zakresie, aczkolwiek wciąż przy obecnej konfiguracji systemu niemożliwe jest wykorzystanie całości posiadanego ciepła odpadowego, nawet w przypadku gdy część ciepła odpadowego jest kierowana do systemu regeneracji.

\title{
Literatura
}

[1] Mikielewicz D., Mikielewicz J.: Utilisation of bleed steam heat to increase the upper heat source temperature in low-temperature ORC, Arch. Thermodynamics, 32 (2011) 57-70.

[2] Instytut Maszyn i Urządzeń Energetycznych, Politechnika Śląska: Obieg wyjściowy (bazowy), 2010.

[3] Badur J., Ziółkowski P., Kaczmarczyk O., Mikielewicz D.: Współpraca bloku energetycznego o mocy 900MW z układem ORC z etanolem i pentanem jako czynnikami roboczymi, oprac. wewn. IMP PAN, 219/2012.

[4] Refprop v. 9.0, National Institute of Standards, 2010.

Przedstawione wyniki zostaty uzyskane $w$ badaniach wspótfinansowanych przez Narodowe Centrum Badań i Rozwoju w ramach umowy SP/E/1/67484/10 - Strategiczny Program Badawczy - Zaawansowane technologie pozyskiwania energii: Opracowanie technologii dla wysokosprawnych ,zero-emisyjnych” bloków węglowych zintegrowanych z wychwytem $\mathrm{CO}_{2}$ ze spalin.

\section{ANALYSIS OF THE POSSIBILITY OF COOPERATION OF THE 900MWe POWER PLANT WITH THE HEAT RECOVERY SYSTEM SUPPLYING ORC}

\begin{abstract}
S u m m a r y
In the paper the issues related to utilisation of waste heat from the power unit of power station at supercritical parameters and plant rating of $900 \mathrm{MW}$ are analysed. The scrutinized problem is a full utilization of heat from heat recovery from exhaust gases, which is available in the form of flow rate of water with temperature of $90^{\circ} \mathrm{C}$ and plant rating of $200 \mathrm{MW}$. The temperature of heat source is too small to obtain attractive efficiency of ORC, hence the cycle is additionally heated by heat from the steam bleeds. The paper presents a numerical model of the hybrid system combining supercritical 900MWe block with the ORC cycle. Furthermore, the calculations of supercritical block for the case where ethanol is used as working fluid and two bleeders are used for evaporation of the ORC agent. To analyze the operating parameters of the cycle Aspen Plus commercial code was used.
\end{abstract}

Keywords: heat recovery, organic Rankine cycle, electrical power engineering

DOI: $10.7862 / \mathrm{rm} .2014 .46$

Otrzymano/received: 25.05.2014

Zaakceptowano/accepted: 28.06.2014 